DOI: https://doi.org/10.47405/mjssh.v6i4.733

\begin{tabular}{|c|c|}
\hline 4 & Malaysian Journal of Social Sciences and Humanities (MJSSH) \\
\hline $\begin{array}{l}\text { Malaysian Journa of } \\
\text { Social cciences and }\end{array}$ & Volume 6, Issue 4, April 2021 \\
\hline (MJ-sSH) & e-ISSN : 2504-8562 \\
\hline & $\begin{array}{l}\text { Journal home page: } \\
\text { www.msocialsciences.com }\end{array}$ \\
\hline
\end{tabular}

\title{
Using Soleh English (SE) Teaching Materials with The Integration of Cultural and Islamic Values: Islamic Preschool Teachers' Voices
}

\author{
Siti Hajar Hassim ${ }^{1}$, Azlina Abdul Aziz ${ }^{1}$ \\ ${ }^{1}$ Faculty of Education, Universiti Kebangsaan Malaysia (UKM) \\ Correspondence: Siti Hajar Hassim (p101716@siswa.ukm.edu.my)
}

\begin{abstract}
English Language Teaching (ELT) materials are significant as tools in facilitating a second language teaching and learning, including preschool level. Also, it is necessary for teachers to opt for appropriate ELT materials which encompass cultural and local identity to generate a meaningful and relatable context of teaching and learning. Nonetheless, most of the materials currently available for preschool education in the publishing market are foreign and therefore little focus on local context. It is more evident in Islamic preschools, as the ELT materials need to be infused with Islamic values to align with the philosophy of Islamic preschools. Hence, this paper presents and discusses a part of a study on Islamic preschool teachers' perception of the Soleh English (SE) teaching materials developed in the attempt to integrate Malay culture and Islamic values with ELT. The study employed a Case Study design involving five female Islamic preschool teachers in the Klang Valley Region. They were purposely chosen based on their experiences using the SE teaching materials. The data was obtained through semi-structured interviews and triangulated with a questionnaire and document analysis. The interview data reported in this article were thematically analysed. Findings illuminated four key themes for each research question which indicated that there is an integration of cultural and Islamic values in SE teaching materials as well as in ESL teaching. This enabled the teachers to instil Islamic and cultural values in their English language teaching in contribution to generate noble citizens.
\end{abstract}

Keywords: materials, ESL teaching, integrated values, Islamic preschool, cultural

\section{Introduction}

English Language is officially regarded as a second language in Malaysia. Due to the importance of the language in Malaysia and also worldwide, the Common European Framework of Reference (CEFR) was officially introduced by The English Language Standard and Quality Council (ELSQC, 2015) as the new scale of worldwide evaluation for English Language education in Malaysia. Preschool level is the earliest level for this policy to be implemented. Hence, ELSQC (2015) has taken the initiative to align the CEFR with the existing preschool curriculum standard or formally known as the National Standard Preschool Curriculum (NSPC) by the Ministry of Education (Ministry of Education, 2016).

The mutual agreement achieved by both CEFR scale and NSPC (Ministry of Education, 2016) in English subject is learning English by using meaningful activities among the preschoolers (ELSQC, 2015). In accordance to that, English language teaching (ELT) materials are found as one of the significant elements needed as a tool in facilitating meaningful activities to the students in the teaching and learning process of a second language (Tomlinson 2011). Generally, ELSQC (2015) further stated 
that the preschool teachers have been supplied with various ELT materials such as CDs, Big Books, Phonetic books and so on by the Curriculum Development Division (CDD) to facilitate them in their ESL classroom. So, teachers are given the flexibility to opt for the materials according to the need of the students. It is mentioned by Aziz, Hameed, Mohamad, Narayanasamy and Yunus (2020) whereby the teachers are the ones responsible for selecting appropriate teaching materials which suit the learners' needs in schools. However, ELSQC (2015) stated that the materials are found to be underused since they are only supplementary and additional ELT materials. As for the teachers, they prefer to utilize materials which are structural, complete and core ELT materials such as textbooks or modules to aid them in their classroom activities. Hence, teachers and preschool owners need to purchase their own complete ELT materials available in the publishing market, which according to Aziz, Narayanasamy, Mohamad and Abdul (2019), could suit the students' level of proficiency to assist them in ESL classroom teaching.

However, despite existing teaching materials available in the publishing market, it is quite difficult to find a complete, core and existing teaching materials which are localized, cultural and infused by Islamic values as stated by Bakar, Rasyid and Salam (2019), whereby findings have shown that the English teachers, especially those who are teaching in Islamic preschools claimed that they experience difficulties when it comes to selecting appropriate materials for their pupils in English Language teaching. They have to adhere to the philosophy of the Islamic preschool in nurturing children with cultural and Islamic values as they hold the parents' trust and responsibility to educate the pupils in such a way (Rahman \& Alias, 2020). In terms of the content of the ELT materials for instance, in one of the topics included the ELT materials is focusing on several celebrations namely Easter, Valentines and so forth which are not familiar in our culture and religion. Hence, they further claimed that the teachers need to encounter the situation by explaining to the preschoolers on the differentiation in terms of culture and religion. It is supported by Tomlinson (2011) whereby the teaching materials for second language learning should be localized to attain the students' comprehension and able to relate with their own situations. In addition, it is also in line with the statement in The Roadmap of the English Education (ESLQC, 2015) for the preschool ELT materials whereby teaching materials should be localized and culturally infused. So, the teachers have to find their own alternatives by developing and searching for their own ELT materials each time they enter classes to ensure the inclusion of the English language, Islamic and cultural values.

Nonetheless, according to Janelle (2019), we have to be considerate and realistic with the teaching scenario whereby teachers should be assisted with complete and structured teaching materials so that they could focus on the preschoolers' achievement and also development, instead of devoting most of their times searching and inventing the materials needed. Bakar et. al (2019) clearly stated that the teachers are willing to invest on the complete ELT materials with the intended criteria for Islamic preschools. For school management, money is not a serious consideration when it comes to the necessity or requirement of the teaching materials. Hence, this paper presents and discusses a part of a larger study on Islamic preschool teachers' perception of the Soleh English teaching materials developed in the attempt to integrate Malay cultural and Islamic values in teaching English language.

More specifically, the research questions that guided this paper are:

i. How are the cultural and Islamic values integrated in the Soleh English teaching materials as perceived by the Islamic preschool teachers?

ii. How do the Soleh English teaching materials assist the Islamic preschool teachers in inculcating cultural and Islamic values through their English Language Teaching?

The remainder of the paper is structured into four parts. First, it reviews the extant literature relevant to the SE teaching materials. Then, the research methodology is presented and data analysis were discussed. Next, the findings are discussed and summarized. The paper concludes with a conclusion, implications and recommendations for further research. 


\section{Literature Review}

\section{The Integration of Values in NSPC (2016)}

\section{Integrated Approach}

One of the teaching and learning strategies stated in the NSPC (Ministry of Education, 2016) is by implementing an integrated approach in teaching certain subjects to the preschoolers. It stated that Integrated approach is defined as two or more skills retrieved by the students in a lesson or subject. According to Yimwilai (2015), this approach could also be referred as multidisciplinary Approach since it has integrated the concept of teaching for more than a subject in certain fields, approaches, disciplines or areas. The examples of integrated approach mentioned in NSPC (Ministry of Education, 2016) are the integration of different skills, integration among strands, integration on activities and techniques in teaching and learning, as well as the integration of skills and values. It means that the teaching and learning in the classroom itself is to be related with the pupils' experiences in their daily lives. It is significant in order to expose to the pupils that formal learning and also daily situations are actually interrelated and not to be practised individually. Luca (1981) stated that by implementing this approach in the teaching and learning, the pupils are able to develop themselves in various abilities and also able to apply it in problem solving situations in any circumstances, as they have learnt on how to deal with them through the lesson. Hence, we as teachers need to accept the pupils' background differences and it is crucial to prepare them for a real-life situation (Qin \& Nor, 2018). In relation to SE teaching materials, apart from learning English, the pupils are able to retrieve and relate the subject with Islamic and cultural values which has fulfilled one of the aspects of integrated approach, and they would be able to apply it in their lives.

\section{Elements Across the Curriculum}

In addition, the integration of values is also stated in the elements across the curriculum, which also acts as one of the elements in conducting a preschool lesson for NSPC (Ministry of Education, 2016). It stated that Elements across the curriculum is defined as the element of additional value embedded in the lesson apart from the main content standards of the subject learnt. These elements are significant to make the pupils well versed in dealing with the circumstances in lives and their future. There are ten elements explained in the NSPC (Ministry of Education, 2016). The two main elements emphasized here are in terms of the Medium of Instruction, particularly for English language and also Values. As for the Medium of Instruction, the instruction is to be clear with the correct pronunciation, sentence structure and also grammar to generate meaningful communication. In terms of Values, they are essential and need to be emphasized on the importance of practising the values in their daily lives. It also stated that values consist of spirituality, humanity and citizenship whereby all of them are basically the things that we face in our daily lives. In relation to SE teaching materials, the element across curriculum is emerged by using English language as a medium of instruction as well as emphasizing the importance of Malay cultural and Islamic values in the teaching materials.

\section{The Overview of SE Teaching Materials}

According to Zakariya (2017), Soleh English (SE) Teaching materials are developed with the basis of 'Soleh' characteristics which is derived from the Arabic word. It means to become good, virtuous, right and in a proper state. Besides, these teaching materials produce Soleh content in terms of English language, consisting of the Islamic Children Song (ICS) taught by the educators to the students. The next phase is Soleh process, which is the practicality of teaching and learning of the students through language games and worksheet provided in the material with the basis of ICS, and lastly is the Soleh values retrieved after getting the input from the various materials that they have practised, in terms of $a d a b$ or known as manner in our culture, and also character building towards a good (soleh) person. 


\section{The Elements in SE Teaching Materials}

SE teaching materials are designed for the preschool teachers to engage the pupils with the use of simple English in a good manner as Muslims, stress-free and also in a fun learning way. It is somehow aligned with the CEFR level for the preschool which is A1, whereby A1 is the basic level for the English subject's evaluation (ELSQC, 2015). As supported by Ibn Khaldun (1986), in order to obtain a meaningful learning, the lesson should be conducted in stages in accordance with the pupils' level. Hence, the lesson should begin with the easy level, and after the pupils are able to obtain the lesson objectives, then they would be proceeded to the higher level. It contains 40 weeks lessons, whereby the teacher is required to practise SE teaching materials only once a week for 35 minutes to encourage the pupils to use and speak simple English in a fun way and also practise good manner of English at the same time. These materials encompass basic English skills in each stage of the lesson. As for the teachers, normally they would opt for Friday class for the lesson considering it as a blessed day in a week for the Muslims.

Figure 1: The Elements in SE Teaching Materials

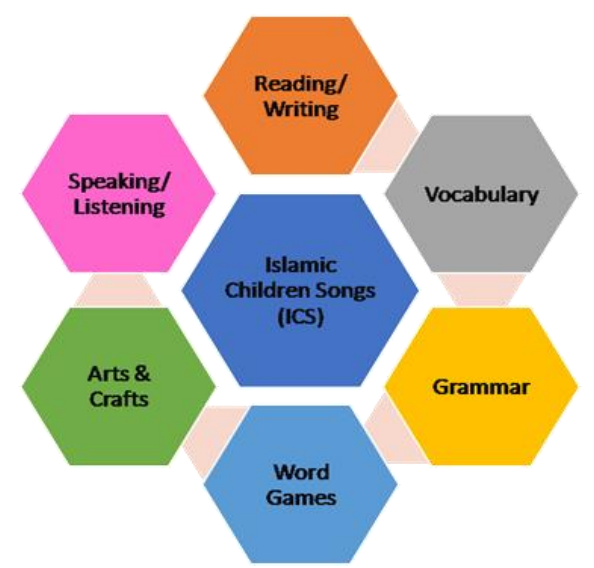

Each lesson is divided into four stages (Warm up and Review- Lesson of The Day-Games and Activities-Recap Learning and Closing Time). As for the first stage which is Warm Up and Review, it is compulsory for the lesson to begin with the Oath as a Soleh English student and The $D u^{\prime} a$ for learning English which have been provided in the SE workbook. Next is reviewing the previous lesson to recap what they have learnt during the previous lesson and also a quick warm-up game.

The second stage is the input of these teaching materials, which is Lesson of The Day. The pupils are informed on the mission of today's lesson and they would begin by singing the Islamic Children Song (ICS). There are seven songs in SE teaching materials. The rhythms of the songs are adopted from nursery rhymes and also Malay cultural children songs to ease the teacher and the pupils in singing the songs by their own, since they are familiar with the rhythm. Apart from that, it is a part of promoting Malay cultural songs and also to show that these songs are still relevant nowadays and need to be preserved. ICS become the domain of the lesson whereby the content of each song consists of the phrases or the subject that they are going to practise for the lesson. Each lesson would include on how to express the phrase in a well-mannered way and also in line with the Islamic values to be practised in their daily conversation. At this stage, the phrases are also being taught and the pupils would get the input by repeating the pattern of the questions and the answers with the teachers.

The third stage is the output (Games and Activities) whereby the pupils practise the phrases in the various language games provided in the materials and to be conducted by the teachers. Beyond this fun-factor, language games could assist the students in strengthening the skills that they have learnt earlier. Some of the games are derived from cultural games namely 'Pukul Berapa Datuk Harimau' (The Hungry Teacher) and $O$ 'som (Hunter, Eagle, Snake). Besides, some activities such as using 
arts and crafts are also involved in this stage. Finally at the last stage (Recap Learning and Closing Time), the pupils end their lesson by recapping the lesson learnt, as repetition is a key to mastery, particularly for the preschoolers (Mohamed, Jasmi \& Abdullah, 2015), and also reciting the Oath and the $D u^{\prime} a$ for learning English again to embrace the significance as Muslims to ask for assistance from the Creator as the priority. Simultaneously, it would strengthen their faith and religious values while learning the language.

In a nutshell, SE teaching materials are attempted to inculcate the Islamic and Cultural values in the materials as well as in ESL teaching and learning. One of the characteristics of good teaching materials in terms of preschool learning is, it should include what is expected from the curriculum, particularly in NSPC and also CEFR-Malaysia. In the context of this study, the teaching materials must encompass cultural and Islamic values to be aligned with the integrated approach as well as elements across the curriculum.

\section{Methodology}

\section{Research Design}

A Case Study was opted as the research design in this study as supported by Lodico, Spaulding and Voegtle (2010), whereby this research design was used to conduct the study which involves studying in depth on a particular program, event, school or group. As for this paper, it aimed to explore on Islamic preschool teachers' perception of the Soleh English teaching materials on the integration of cultural and Islamic values.

\section{The Participants and Research Site}

Five female preschool teachers were purposely chosen as participants of this study. As the criterion of the participants, they should be teaching in Islamic Preschools and have had experiences in teaching English as well as using the SE materials in their classrooms for at least 2 years and above. In sum, the demographic information of the participants are as follow:

Table 1: Demographic Information of The Participants

\begin{tabular}{ccccc}
\hline Participant & Age & $\begin{array}{c}\text { Educational } \\
\text { Background }\end{array}$ & $\begin{array}{c}\text { Years of } \\
\text { teaching } \\
\text { Preschool }\end{array}$ & $\begin{array}{c}\text { Years of using SE } \\
\text { teaching materials in } \\
\text { ESL teaching }\end{array}$ \\
\hline $\begin{array}{c}\text { Participant 1 } \\
\text { (P1) }\end{array}$ & 34 & Biology (Science) & 11 years & 2 years \\
$\begin{array}{c}\text { Participant 2 } \\
\text { (P2) }\end{array}$ & 32 & STPM & 13 years & 4 years \\
$\begin{array}{c}\text { Participant } 3 \\
\text { (P3) }\end{array}$ & 34 & $\begin{array}{c}\text { Degree in } \\
\text { Accountancy }\end{array}$ & 7 years & 2 years \\
$\begin{array}{c}\text { Participant 4 } \\
\text { (P4) }\end{array}$ & 32 & $\begin{array}{c}\text { STPM/SKM Early } \\
\text { Childhood Education }\end{array}$ & 12 years & 3 years \\
$\begin{array}{c}\text { Participant 5 } \\
\text { (P5) }\end{array}$ & 33 & $\begin{array}{c}\text { Dip. In Early } \\
\text { Childhood Education }\end{array}$ & 7 years & \\
\hline
\end{tabular}

The teachers were purposely selected from five preschool branches of an established Islamic Kindergarten in Selangor, namely Dzul Iman Smart Khalifah Centre. It is an established Islamic kindergarten which practises Khalifah Method and believes in a positive teaching approach and 
learning to appreciate their relationship with Allah SWT. Besides, it is among the earliest centre which has been utilizing these teaching materials since 2017 until present (Dzuliman, 2020).

\section{Instrumentation}

An online semi-structured interview has been chosen as the research instrument for this study. It is supported by Tuckman (1999) whereby interview is the major instrument in qualitative studies. The application of WhatsApp messenger was the medium for interview sessions. In order to explore the use of the SE teaching materials in their teaching, the researchers have used this instrument to elicit in-depth data (Mihat, 2015). The list of questions was prepared by the researchers in the form of a softcopy. There were 5 parts in the list of questions. Part A consisted of the respondents' demographic backgrounds namely gender, education background, years of teaching and also years of using the SE teaching materials in their teaching. Part B consisted of the questions on the use of SE teaching materials in English Language Teaching. Part C consisted of the questions on the use of SE teaching materials in the integration of Islamic and cultural values, whereas Part D consisted of the pupils' response to the SE teaching materials. Part E consisted of Parents' Response on the use of SE teaching materials and lastly was Part F which was the challenges and recommendation to the materials in ESL teaching.

\section{Data Collection Procedure}

The questions were asked by the researchers to the interviewees via online WhatsApp messenger. The researchers text the questions and the interviewees answered the questions in two ways, via voice notes and also text messages, depending on their preferences. Then, the voice notes and the messages were transcribed and arranged according to the list of questions.

\section{Method of Data Analysis}

The collected data through online semi-structured interviews were transcribed from audio form to textual form, and also from Bahasa Melayu to English. Next, thematic analysis was used to categorize the findings into themes and sub themes by referring to the mutual ideas and keywords retrieved from the interview transcriptions. Finally, the data were presented according to the thematic analysis.

\section{The Trustworthiness of the Data}

In order to ensure the trustworthiness of the instrument and data analysis, a preliminary study was employed to an English and teacher who also has experienced using SE teaching materials to teach English in her preschool. It is significant to gauge the suitability of the questions to be asked among the preschool teachers. Besides, the preliminary study was also employed to test whether the interview questions are able to reveal the findings and the purpose of the study (Lodico et al., 2010). The interview questions were then amended according to the feedback from the preliminary study. Moreover, participation validation of the interview transcript was also involved to ensure that the transcription was translated and written in parallel with the participants' point of view during the interview session (Aziz \& Yamat, 2020). In terms of methodological triangulation, the data was also triangulated with two other instrumentations namely questionnaire and document analysis which were included in the larger research.

\section{Findings and Discussion}

The findings of the study were being identified to answer the following research questions which are (1) How are the cultural and Islamic values integrated in SE teaching materials as perceived by the Islamic preschool teachers? and (2) How do SE teaching materials assist the Islamic preschool teachers in inculcating cultural and Islamic values through their English Language Teaching? 
According to the online semi-structured interview with the purposely chosen participants, It has somehow answered both of research questions in the study. As for the first research question, the findings were identified by using thematic analysis of the transcribed interview scripts. The findings have emerged four key themes with four sub themes namely (1)The Oath and $D u^{\prime} a$ for Learning English, (2) Islamic Children Songs (ICS), (3) Modest Visualisation and (4) Cultural Language Games. As for the second research questions, four key themes emerged which are (1)Non-threatening Atmosphere, (2) Different Learning Styles (3) Language Elements and (4) Manner of Interaction. There are seven sub themes emerged under these four key themes as stated in the findings.

\section{RQ1: How are the cultural and Islamic Values integrated in SE teaching materials perceived by the Islamic preschool teachers?}

\section{(1) The Oath and Du'a for Learning English}

Based on the findings retrieved from the five participants, all of them have stated a mutual perception whereby The Oath and The Doa for learning English is the most significant integration in these teaching materials. As represented by two of the participants:

"I think this is my first time using the English module included with the specific Oath and Du'a before learning English, and it shows that we could relate it with Allah SWT.. and the Du'a is recited in a song which is interesting.." (P3)

"It's so special to have Doa and Oath in English materials which we didn't think of having it before this.."(P4)

Hence, the students are able to relate that Islamic values do not only exist in Islamic Education lesson, but it is a holistic learning whereby it also could be integrated in ELT materials.

\section{(2) Islamic Children Songs (ICS)}

\section{(a) Catchy and Easy Listening}

As mentioned before, SE teaching materials consist of ICS as the domain of each lesson. All of the five participants also agree that the songs are catchy and also easy to be taught. As stated by two of the participants below:

"The songs are simple and the students could easily sing the song.... (P1)

"The songs are catchy.. and the students can easily learn even though they aren't familiar with the song...we as teachers just use our own voice to sing it..." (P4)

Furthermore, the songs could be demonstrated solely by the teacher without any sophisticated instruments or minus one due to the catchy and familiar rhythms.

\section{(b) The Element of Islamic and Cultural Songs}

There are several songs which represents cultural and Islamic elements as mentioned below:

\footnotetext{
"The lyrics contain Islamic terms such as Masjid, Allah Arraheem, Mr Bilal...." (P3)

"and there are several songs which are cultural Malay Song like Can Malican, Rasa Sayang and Bapaku Pulang which the students are not really familiar with...”(P1)
} 
Simultaneously, the pupils also could acquire the Islamic terms and also Malay cultural Song which they rarely listen to, as they are new generations. So, this would preserve the culture through Malay classical song as well.

\section{(3) Modest Visualisation}

\section{(a) Workbook}

'The workbook is colourful and with modest characteristics and graphic...' (P1)

In the workbook, the characters and the illustration used in the book is based on the concept of modesty and in line with the Islamic and Malay culture. Modest here is meant by proper attire and also did not involve any foreign elements in the workbook. For instance, the male characters are wearing proper long trousers while the female characters are wearing long dresses and some of them are also wearing hijab. So, these have portrayed the element of Islamic and also modesty in our Malay culture.

\section{(c) Flashcards}

'The flashcards are also interesting, vivid and also potray the muslim institution such as masjid and so on...we use masjid instead of mosque..." (P4)

In terms of the flash cards, it has the Islamic element whereby one of the examples is the image of masjid in the flashcard. Moreover, in the lesson entitled 'Where are you Going', they used the exact term of masjid instead of the term 'mosque' to bring the pupils closer to the Islamic values as it is the symbol of Islamic institution.

\section{(4) Cultural Language Games}

"It also involves the Malay traditional game namely Pukul berapa Datuk Harimau or The Hungry Teacher. So, the students could learn on how to play the traditional games.. "(P1)

As we know that the cultural games are almost unheard by the new generation nowadays due to the massive existence of virtual games. So, the cultural games are being neglected in their childhood time. So, it is a good initiative to preserve and embed cultural games in SE teaching materials.

\section{RQ2: How do SE teaching materials assist the Islamic preschool teachers in inculcating cultural and Islamic values through their English Language Teaching?}

\section{(1) Non-threatening Atmosphere}

According to Pourkalhor \& Tavakoli (2017), non-threatening atmosphere is significant in learning a second language so that the pupils would experience less anxiety in dealing with the second language. One of the elements which lead to this atmosphere is through learning while playing. The elements in SE materials in ESL classroom which lead to the non-threatening atmosphere are as follows:

\section{(a) Learning while Playing}

According to Abdullah, Nor, Damaety and Chee (2017), preschool teachers need to implement 'playing' situations in their classroom teaching to ensure that the pupils would simultaneously retrieve the gist of the lesson while playing. In this case, the integrated values embedded in the 
English lesson would be perceived by the pupils through the 'playing' activities as mentioned below:

"Yes, it is a fun learning and the students did not realize that they are actually learning good

English through the session.."(P3)

"In this module we try to promote no stress for kids or underachievers through fun learning..”.(P5)

"The games arranged are superb and promote the students to use the English freely while playing the games" $(P 4)$

In playing language games for instance, they are somehow concerned with communicating rather than learning English structurally and formally (Yaccob \& Yunus, 2019). So, the students would practise using the phrases while playing the games.

\section{(b) The use of Songs (ICS)}

"Yes, as it include songs and language games which can reduce stress and anxiety for the kids in using English.. "(P4)

According to Augustine (2015), songs could shift the lesson into a positive learning environment since we are normally singing songs when we are feeling delighted or excited. Simultaneously, we bring up the informal environment in our language learning and this will lead to fun learning activities.

As a result, these conditions would be effective for the pupils in retrieving the language and at the same time they get the Islamic and cultural values contained in the teaching.

\section{(2) Various Learning Styles}

Moreover, SE teaching materials have promoted various learning styles namely visual, auditory and kinaesthetic (VAK) for ESL teaching. It is supported by Maasum, Mustaffa and Stapa (2015) whereby language input can be intelligible by using different kinds of strategies namely visual aids, auditory materials, linguistic simplification, mind maps and others. As mentioned below:

"The activities in games and songs especially really involves VAK such as pasting stickers, clapping hands, catching people..”(P1)

"The process of cutting the pictures and the games promote the VAK (fine motor skills and gross motor skills)...”(P2)

Simultaneously, the various learnings styles would lead them to embrace more values inculcated in SE teaching materials effectively.

\section{(3) Language Elements}

\section{(a) English Skills}

In mastering English, these four skills namely speaking, listening, reading and writing need to be mastered by the language learners, from preschool up to higher education. (Yaccob \& Yunus, 2019). As for SE teaching materials, it has catered the basic of four English Skills in English teaching:

“As for basic four skills, I think it covers mostly for basic level..”(P3) 
"Yes, it covers the four skills and also integrated it with Islamic values but in a surface way, suitable fo the preschoolers.."(P1)

It is known that the basic level to be obtained among preschoolers in CEFR Malaysia is A1. So, SE teaching materials have assisted teachers in obtaining A1 level through the language skills covered in the materials.

\section{(b) Repetition}

As mentioned before, Ibn Khaldun (1986) stated that repetition in learning could tighten the memory in the long term. Hence, it has shown that the materials are concerning on repetition to master the language use:

'Because we keep trying to encourage the students with repetition in using phrases to build confident level on the students... '(P5)

'The song is easy to introduce because it involves repetition so the students could easily memorize the song... ' (P2)

Repetition is a key to mastery as the nature of preschool learning is to use repetition in their learning (Mohamed et al. 2015). Simultaneously, the repetition would lead them to comprehend more in English as well as practising the values learnt.

\section{(c) Simple Phrases}

In these teaching materials, each topic would have its own phrases or sentence patterns with the questions and also replying the conversation (Zakariya, 2020) which by far is practical to be exposed to the pupils in using the English language as mentioned below:

"This module used simple conversation which we always used daily, it's not the advanced phrases. Ya, since we are not an English native speaker, so I think it is practical to use simple English especially for the preschoolers like them..."(P1)

"The phrases like how are you,,, how old are you...where are you goings, are simple.. but important for the students as their first step in speaking the language..." (P5)

Simultaneously, the students would know how to speak simple English and be suitable with their level of proficiency as preschoolers. Since English is our second language in Malaysia, so the use of simple words would ease our preschoolers in learning and obtaining the values.

\section{(4) The Manner of Interaction}

\section{(a) Interaction with Allah SWT}

As Muslims, we know that in every single thing that we intend to do in our lives, we must seek from Allah and also ask blessings from Him. Based on the interview, SE teaching materials somehow assist the teachers to guide the pupils to ask for Allah as a priority when we want to learn or getting something, as mentioned below:

"They know that from the oath and doa, it means that we have to seek Allah first in whatever we do in our lives..." (P2)

Du'a before learning is totally different and special compared to other materials that we used before..(P4) 
So the Islamic values particularly the element of Tauheed (worshipping Allah is the only God) is somehow instilled among pupils and simultaneously, they would practise it in their daily lives which is beyond the circle of classroom settings.

\section{(b) Interaction among People}

In addition, SE teaching materials have nurtured the pupils in using good English conversation in a good manner, and it is in line with our Malay culture which is modest in interacting with people. Besides, it encourages the pupils to use zikr phrases such as Ma shaa Allah, Alhamdulillah and Assalamualaikum as mentioned below:

"Mostly this module managed to instill the good manner when conversing, and asking permission when speaking and also replying the conversation with the teachers and friends...for example during class, the students would practise : "Assalamualaikum..Excuse me Ustazah, May I ask you something? Yes, Alhamdulillah I won the game!

May I go to the toilet "please".. "Astaghfirullah, I'm sorry friends".... " (P1)

"This module could teach students on how to greet people politely and also on how to begin and asking permission to speak something, even though in playing games.."(P3)

So, they would bring the lesson learnt in their real-life situations as it has met the purposes of integrated Approach (Ministry of Education, 2016) which is to implement the values in their real life situation. Most importantly, they are able to retrieve proper and correct sentence patterns during English conversation.

Based on the findings revealed among the participants, it is evident that the integration of cultural and Islamic values in SE teaching materials exists and also perceived by the Islamic preschool teachers in English language teaching, with the assistance of The oath and Doa for learning English to tighten the relationship with Allah SWT. Besides the Malay cultural and Islamic songs, the Malay cultural games and simple phrases are also inserted to capture the pupils' attention and have made the pupils to immerse themselves in the lesson through a non-threatening atmosphere. Consequently, it would encourage the pupils to use English confidently and most importantly, in a good manner which suits our cultural and Islamic values.

\section{Conclusion}

In parallel with the need of integration of values in NSPC (Ministry of Education, 2016), teachers as the main reference particularly for the preschoolers should utilise these teaching materials as for their teaching aids, so that the teachers would kill two birds in one stone, by teaching the English language as well as instilling the good values. In other words, it means that each of the subjects taught could not stand solely by its own (Qin \& Nor, 2018). Whereas, it should be conjoined with other values which also lead to the existence of the element across the curriculum, so that the pupils would be able to foresee their lesson as beneficial and meaningful knowledge instead of only theoretical-based knowledge. Children nowadays are doomed to be less emotional due to the devotion towards technology and less attachment with human and nature. So, we have to adhere to the nature of life namely our religion and our culture which would lead us to the actual purpose of our life. Hence, in order to humanize our children, particularly for the earliest level as preschoolers, we as teachers as well as the lesson planners should initiate the meaningful lesson by integrating and exposing our pupils to these kinds of values, in terms of good attitude and behaviour, especially when it comes to learning a second language. Despite the position of English as a second language in Malaysia, and often related to foreign countries, it does not seem that we need to neglect our culture and religion. It is because learning language is something which is global and not restricted to certain tribes or races. 


\section{Implications and Recommendations}

Lastly, it is hoped that the study would benefit the educators in searching for good teaching materials with the integration of cultural and Islamic values which in return would nurture the good values to our students. Besides, for the head administration of Islamic school organisation, they also should take this issue into their consideration which is by developing their own curriculum and teaching materials with the infusion of Islamic and Malay cultural values, so that the teachers would utilise it in parallel with the philosophy of the Islamic school. Moreover, it could be the catalyst and encouragement for the material developers to develop more modules and teaching materials with the integration of good values in English language teaching as well as other subjects in school. Perhaps it would be more inventions on material developments for the primary and secondary level so that the continuation of the lesson and values would lead them to be better citizens.

\section{References}

Abdullah, M., Nor, M. M., Damaety, F., \& Chee, J. (2017). Teaching Approaches in the Classroom among Preschool Teachers. International Journal of Academic Research in Business and Social Sciences, 7(3), 748-755.

Augustine, C. (2015). How The Use of Music and Movement Impacts The Learning Of Reading Skills By Preschoolers. Malaysian Journal of Music, 4(2), 74-90.

Aziz, A. A., Hameed, H. A., Mohamad, M., Narayanasamy, J., \& Yunus, M. M. (2020). Pre-Service Teachers Experiences in Developing Reading Materials for the Teaching of Reading in an ESL Classroom. International Journal of English Language and Literature Studies, 9(3), 185-195.

Aziz, A. A., Narayanasamy, J., Mohamad, M., \& Abdul, H. H. (2019). Student-teachers‘ experiences in creating oral history texts. 3L: The Southeast Asian Journal of English Language Studies, 25(3), 79 - 89. Available at: http://doi.org/10.17576/3L- 2019-2503.

Aziz, A.A \& Yamat, H. (2020). Qualitative research design. Bangi, Selangor: Penerbit Universiti Kebangsan Malaysia.

Bakar, A. A., Rasyid, R.A., \& Salam, W. N. W. (2019). Facilitating Classroom for English Learning and Curriculum Implementation in Preschool Education. Journal of Research and Opinion, 6(10), 2490-2494.

Dzuliman (2020). DzulIman Smart Khalifah. https://dzuliman.com/ [25 November 2020] English Language Standard Quality Council (2015). English Language education reform in Malaysia: The Roadmap 2015- 2025.

Ibn Khaldun. (1986). Al-Mukaddimah. Beirut: Al-Maktabah Hilal.

Janelle, C. (2019). Here's what you need to know about lesson plans. https://www.thoughtco.com/what-is-a- lesson-plan-2081359. [28 November 2020].

Lodico, M. G., Spaulding, D. T., \& Voegtle, K. H. (2010). Methods in educational research: From theory to practice (Vol. 28). John Wiley \& Sons.

Lucan, T. A. (1981). Social Studies as an Integrated Subject. In H. D. Mehlinger (Ed.), UNESCO handbook for the teaching of social studies: UNESCO.

Maasum, T. N. R. T. M., Mustaffa, R., \& Stapa, S. H. (2015). Young Learners' Perceptions of Learning English Using Language Games in a Non-Formal Context. Mediterranean Journal of Social Sciences, 6(6 S5), 375.

Mihat, W. (2015). The English language curriculum in Malaysian indigenous primary classrooms: The reality and the ideal. 3L: Language, Linguistics, Literature, 21(3).

Ministry of Education Malaysia. (2016). National Preschool Standard-based Curriculum.

Mohamed, S., Jasmi, K. A., \& Abdullah, A. (2015). Teaching and learning of Islamic education preschool teachers in the classroom: a preliminary study. In Asia International Conference 2015: Future of Marketing and Management.

Pourkalhor, O., \& Tavakoli, M. (2017). Nursery rhymes and language learning: Issues and pedagogical implications. International Journal of English Language \& Translation Studies, 5(1), 111-116.

Qin, T. Y., \& Nor, M. M. (2018). Exploring issues on teaching and learning in Malaysian Private Preschools. MOJEM: Malaysian Online Journal of Educational Management, 6(2), 67-82. 
DOI: https://doi.org/10.47405/mjssh.v6i4.733

Rahman, S. R. T. A., \& Alias, A. (2020). Faktor Pemilihan Tadika Swasta Islamik oleh Ibu Bapa: Satu Kajian Kes di Daerah Marang, Terengganu [Factors of Choosing Islamic Preschool by Parents: A Case Study in Marang, Terengganu]. BITARA International Journal of Civilizational Studies and Human Sciences, 3(3), 49-64.

Tomlinson, B. (Ed.). (2011). Materials development in language teaching. Cambridge, UK: Cambridge University Press.

Tuckman, B. W. (1999). Conducting educational research (ed.). Florida: Harcourt Brace College Publishers.

Yaccob, N. S., \& Md Yunus, M. (2019). Language Games in Teaching and Learning English Grammar: A Literature Review. Arab World English Journal, 10(1).

Yimwilai, S. 2015. An Integrated approach to teaching literature in an EFL classroom. English Language Teaching, 8(2), 14-21.

Zakariya, R. 2017. Welcome to Soleh English. https://solehenglish.com/ [22 November 2020]

Zakariya, R. 2020. Soleh English Activity Books For Teachers. Subang Jaya: Soleh English Learning System PLT. 